\title{
HUBUNGAN MUTU PELAYANAN TENAGA KESEHATAN DENGAN KEPUASAN PASIEN RAWAT JALAN RUANG POLI UMUM DI PUSKESMAS SEI AGUL MEDAN
}

\author{
Muhammad A. Kurnia*, Rosalina Gultom, Ermi Girsang, Masryna Siagian \\ Fakultas Kesehatan Masyarakat, Universitas Prima Indonesia \\ *(muhammadadityakurnia@unprimdn.ac.id)
}

\begin{abstract}
ABSTRAK
Masyarakat Indonesia pada saat ini membutuhkan pelayanan kesehatan yang bermutu yang dapat dilihat berdasarkan tingkat kepuasan pasien di Indonesia yaitu menunjukkan angka kepuasaan pasien $42,8 \%$. Di Puskesmas Sei Agul terdapat pasien rawat jalan yang menyatakan tidak puas sebanyak 49 orang (51,6\%). Penelitian ini bertujuan untuk mengetahui hubungan mutu pelayanan tenaga kesehatan dengan kepuasan pasien rawat jalan ruang poli umum di Puskesmas Sei Agul. Jenis penelitian yang digunakan dalam penelitian ini adalah survey analitik dengan menggunakan pendekatan Cross-Sectional. Jumlah sampel dalam penelitian ini adalah 95 pasien rawat jalan. Teknik pengambilan sampel yang digunakan adalah Purposive Sampling. Pengambilan data menggunakan alat ukur kuesioner. Analisis data dilakukan secara analisis univariat dan bivariat (Uji Chi- Square) dengan derajat kemaknaan p Value $=0,05$. Hasil penelitian ini menunjukkan bahwa kehandalan dengan nilai $p$ Value $=0,006(p$ Value $<0,05)$, daya tanggap dengan nilai $p$ Value $=0,002$ ( $p$ Value $<0,05)$, jaminan dengan nilai $p$ Value $=0,003(p$ Value $<0,05)$, empati dengan nilai $p$ Value $=0,386$ ( $p$ Value $>0,05$ ), dan bukti fisik dengan nilai $p$ Value $=0,019(p$ Value $<0,05)$. Kesimpulan dari penelitian ini adalah ada hubungan kehandalan dengan kepuasan pasien, ada hubungan daya tanggap dengan kepuasan pasien, ada hubungan jaminan dengan kepuasan pasien, tidak ada hubungan empati dengan kepuasan pasien dan ada hubungan bukti fisik dengan kepuasan pasien.
\end{abstract}

Kata kunci : : Mutu Pelayanan, Kepuasan Pasien

\begin{abstract}
Indonesian people at this time need quality health services that can be seen based on the level of patient satisfaction in Indonesia that shows the patient's satisfaction rate of 42.8\%. In Sei Agul Puskesmas there are outpatient who expressed dissatisfaction as much as 49 people (51.6\%). This research aims to determine the relationship quality of healthcare professionals with the satisfaction of a general Poly chamber patient in the health center of Sei Agul. The type of research used in this study is an analytical survey using the Cross-Sectional approach. The number of samples in this study was 95 outpatient. The sampling technique used is Purposive Sampling. Data retrieval using questionnaire measuring instrument. Analysis of data conducted in the analysis of Univariate and bivariate (test ChiSquare) with a degree of significance $p$ Value $=0.05$. The results showed that the reliability with the value $p$ value $=$ 0.006 ( $P$ Value $<0.05$ ), responsiveness with the value $p$ value $=0.002$ ( $p$ value $<0.05$ ), the guarantee with the value $P$ value $=0.003$ ( $P$ Value $<0.05)$, empathy with the value $p$ value $=0.386$ ( $p$ value $>0.05)$, and physical evidence with the value $p$ value $=0.019$ ( $p$ Value $<0,05$ ). The conclusion of this research is there is a relationship of reliability with patient satisfaction, there is a response of responsiveness to patient satisfaction, there is a guarantee relationship with patient satisfaction, no empathy relationship with patient satisfaction and there is a relationship of physical evidence with patient satisfaction.
\end{abstract}

\section{Keywords: Service quality, patient satisfaction}

\section{PENDAHULUAN}

Mutu pelayanan kesehatan di Indonesia dalam aspek, jumlah, kualitas dan penyebarannya terus membaik. Pada tahun 2014, capaian persentase fasilitas pelayanan kesehatan yang mempunyai SDM kesehatan sesuai standar sebesar 85,50\% melampaui target yang ditetapkan $80 \%$ dengan demikian capaian kinerjanya $106,88 \%$. $^{1}$

Menurut Profil Kesehatan Kota Medan menyatakan bahwa pemanfaatan fasilitas kesehatan oleh masyarakat dapat dilihat dari jumlah kunjungan ke fasilitas kesehatan yang ada. Puskesmas merupakan fasilitas kesehatan pemerintah sebagai sarana pelayanan kesehatan dasar. Tahun 2015 jumlah kunjungan pasien rawat jalan di Puskesmas se-Kota Medan diperkirakan sekitar 947.987 kunjungan dan tahun 2016 jumlah kunjungan pasien rawat jalan di Puskesmas se-Kota Medan di perkirakan sekitar 1.150.703 kunjungan. ${ }^{2}$

Hasil penelitian yang dilakukan Witter,dkk (2015) dalam Munsil (2017), menyatakan bahwa beberapa hasil penelitian menunjukan data tentang tingkat kepuasan pasien di berbagai Negara. Tingkat kepuasan pasien menurut Ndambuki tahun 2013 di Kenya menyatakan 
40,4\%, kepuasan pasien di Bakhtapur India menurut Twayana $34,4 \%$ sedangkan di Indonesia menunjukkan angka kepuasaan pasien $42,8 \%$. $^{3}$

Hasil penelitian yang dilakukan oleh Jusriani (2016), yang dilakukan di Puskesmas Puriala terhadap 100 responden, responden yang menyatakan kurang puas terhadap pelayanan kesehatan sebanyak 70 responden $(70,0 \%)$, dan responden yang menyatakan cukup puas terhadap pelayanan kesehatan sebanyak 30 responden $(30,0 \%){ }^{4}$

Berdasarkan hasil survey awal yang dilakukan oleh peneliti pada bulan Agustus 2018, diperoleh data Puskesmas Sei Agul yang ditunjang oleh Kepala Puskesmas 1 orang, dokter umum 2 orang, dokter gigi 3 orang, bidan

5 orang, perawat 10 orang, apoteker 1 orang, tenaga kesehatan masyarakat 3 orang, nutrisionis 2 orang dan pranata laboratorium pelaksana lanjutan 1 orang. Data kunjungan pasien rawat jalan di Puskesmas Sei Agul tahun 2015 sebanyak 22656 kunjungan, tahun 2016 sebanyak 28797 kunjungan, tahun 2017 sebanyak 28219 kunjungan dan tahun 2018 sebanyak 27732 kunjungan.

Berdasarkan hasil wawancara yang dilakukan kepada 10 orang pasien di Puskesmas Sei Agul, 2 orang pasien menyatakan bahwa merasa tidak puas dengan waktu tunggu pemeriksaan yang lama dan belum memiliki sistem antrian yang teratur, 2 orang pasien menyatakan tidak puas dengan informasi yang diberikan tenaga kesehatan tentang keluhan yang di derita pasien dan kelambatan tenaga kesehatan dalam melayani pasien, 3 orangHASIL pasien menyatakan tidak puas dengan fasilitas ruang tunggu yang belum memadai seperti fasilitas tempat duduk yang belum memadai sehingga menyebabkan ketidaknyamanan pada pasien dan 3 orang pasien menyatakan puas dengan pelayanan kesehatan yang diberikan tenaga kesehatan.

Berdasarkan permasalahan diatas, maka peneliti tertarik melakukan penelitian tentang Hubungan Mutu Pelayanan Tenaga Kesehatan dengan Kepuasan Pasien Rawat Jalan Ruang Poli Umum di Puskesmas Sei Agul.

\section{BAHAN DAN METODE}

Jenis penelitian yang digunakan adalah survey analitik dengan menggunakan pendekatan Cross-Sectional. Penelitian dilakukan di Puskesmas Sei Agul Medan pada bulan Juli 2019. Populasi dalam penelitian ini adalah semua pasien rawat jalan ruang poli umum di Puskesmas Sei Agul pada bulan Agustus 2018 sebanyak 1.909 pasien. Jumlah sampel dalam penelitian ini adalah 95 pasien rawat jalan. Teknik pengambilan sampel yang digunakan dalam penelitian ini adalah purposive sampling yang ditentukan berdasarkan kriteria inklusi dan eksklusi.

Data primer pada penelitian ini diperoleh dari kuisoner dengan responden yaitu pasien rawat jalan ruang poli umum di Puskesmas Sei Agul. Data sekunder pada penelitian ini di dapatkan dari data kunjungan rawat jalan Puskesmas Sei Agul, serta referensi-referensi yang mendukung dalam penelitian ini. Analisis menggunakan uji chi-square di mulai dari univariat dan bivariate.

\section{Analisis Univariat}

Tabel 1. Distribusi Frekuensi Responden Berdasarkan Umur, Jenis Kelamin, Pendidikan, Pekerjaan dan Lama Berkunjung Pasien Rawat Jalan Ruang Poli Umum di Puskesmas Sei Agul.

\begin{tabular}{ccccc}
\hline No & Karakteristik & Jumlah & Persentase (\%) \\
\hline 1 & & & \\
\cline { 2 - 4 } & 16-25 tahun & 11 & 11,6 \\
& 26-35 tahun & 8 & 8,4 \\
& 36-45 tahun & 31 & 32,6 \\
& 46-55 tahun & 15 & 15,8 \\
& 56-65 tahun & 20 & 21,1 \\
& 66-75 tahun & 10 & 10,5 \\
\hline \multicolumn{2}{l}{ Total } & $\mathbf{9 5}$ & $\mathbf{1 0 0 , 0}$ \\
\hline
\end{tabular}




\begin{tabular}{|c|c|c|c|}
\hline \multirow[t]{4}{*}{2} & \multicolumn{3}{|l|}{ Jenis Kelamin } \\
\hline & Laki- laki & 28 & 29,5 \\
\hline & Perempuan & 67 & 70,5 \\
\hline & Total & 95 & 100,0 \\
\hline \multirow[t]{7}{*}{3} & Pendidikan & & \\
\hline & SD & 17 & 17,9 \\
\hline & SMP & 12 & 12,6 \\
\hline & SMA & 39 & 41,1 \\
\hline & Akademi & 5 & 5,3 \\
\hline & Sarjana & 22 & 23,2 \\
\hline & Total & 95 & 100,0 \\
\hline \multirow[t]{7}{*}{4} & Pekerjaan & & \\
\hline & Tidak ada & 48 & 50,5 \\
\hline & PNS & 11 & 11,6 \\
\hline & Wiraswasta & 21 & 22,1 \\
\hline & Pegawai Swasta & 10 & 10,5 \\
\hline & Pensiunan & 5 & 5,3 \\
\hline & Total & 95 & 100,0 \\
\hline \multirow[t]{4}{*}{5} & Lama Berkunjung & & \\
\hline & $<5$ kali & 47 & 49,5 \\
\hline & $\geq 5$ kali & 48 & 50,5 \\
\hline & Total & 95 & 100,0 \\
\hline
\end{tabular}

Berdasarkan tabel 1, diperoleh distribusi frekuensi kelompok umur dari 95 responden, mayoritas responden kelompok umur 36-45 tahun sebanyak 31 orang $(32,6 \%)$ dan minoritas kelompok umur 26-35 tahun sebanyak 8 orang $(8,4 \%)$.

Berdasarkan distribusi frekuensi jenis kelamin responden, mayoritas responden berjenis kelamin perempuan sebanyak 67 orang (70,5\%) dan minoritas berjenis kelamin laki-laki sebanyak 28 orang $(29,5 \%)$ dan berdasarkan distribusi frekuensi pendidikan responden, mayoritas pendidikan SMA sebanyak 39 orang $(41,1 \%)$ dan minoritas pendidikan Akademi sebanyak 5 orang (5,3\%).

Berdasarkan distribusi frekuensi pekerjaan responden, mayoritas tidak bekerja sebanyak 48 orang $(50,5 \%)$ dan minoritas pensiunan sebanyak 5 orang $(5,3 \%)$ dan berdasarkan distribusi frekuensi lama berkunjung responden, mayoritas berkunjung $>5$ kali sebanyak 48 orang $(50,5 \%)$ dan minoritas berkunjung $<5$ kali sebanyak 47 orang $(49,5 \%)$.

Tabel 2. Distribusi Frekuensi Responden Berdasarkan Pelayanan Kehandalan, Pelayanan Daya Tanggap, Pelayanan Jaminan, Pelayanan Empati , Pelayanan Bukti Fisik Dengan Kepuasan Pasien Rawat Jalan Ruang Poli Umum di Puskesmas Sei Agul.

\begin{tabular}{llll}
\hline No & Variabel & Jumlah $(\mathbf{n})$ & Persentase(\%) \\
\hline $\mathbf{1}$ & Kehandalan & & \\
& Baik & 47 & 49,5 \\
& Tidak Baik & 48 & 50,5 \\
\hline & Total & $\mathbf{9 5}$ & $\mathbf{1 0 0 , 0}$ \\
\hline $\mathbf{2}$ & Daya Tanggap & & 45,3
\end{tabular}


Tidak Baik

\begin{tabular}{llll} 
& Tidak Baik & 52 & 54,7 \\
\hline $\mathbf{3}$ & Total & $\mathbf{9 5}$ & $\mathbf{1 0 0 , 0}$ \\
& Jaminan & & \\
& Baik & 42 & 44,2 \\
& Tidak Baik & 53 & 55,8 \\
\hline & Total & $\mathbf{9 5}$ & $\mathbf{1 0 0 , 0}$ \\
\hline $\mathbf{4}$ & Empati & & 66,3 \\
& Baik & 63 & 33,7 \\
& Tidak Baik & 32 & $\mathbf{1 0 0 , 0}$ \\
\hline & Total & $\mathbf{9 5}$ & 43,2 \\
\hline $\mathbf{5}$ & Bukti Fisik & & 56,8 \\
& Baik & 41 & $\mathbf{1 0 0 , 0}$ \\
& Tidak Baik & 54 & 48,4 \\
\hline & Total & $\mathbf{9 5}$ & 51,6 \\
\hline $\mathbf{6}$ & Kepuasan Pasien & & $\mathbf{1 0 0 , 0}$ \\
& Puas & 46 & \\
\hline & Tidak Puas & 49 & $\mathbf{9 5}$ \\
\hline
\end{tabular}

Berdasarkan analisis univariat Tabel 2, dapat dilihat bahwa pelayanan kehandalan, mayoritas responden menilai tenaga kesehatan adalah tidak baik sebanyak 48 orang $(50,5 \%)$ dan minoritas responden menilai tenaga kesehatan adalah baik sebanyak 47 orang (49,5\%).

Berdasarkan pelayanan daya tanggap, mayoritas responden menilai tenaga kesehatan adalah tidak baik sebanyak 52 orang $(54,7 \%)$ dan minoritas responden menilai tenaga kesehatan adalah baik sebanyak 43 orang $(45,3 \%)$.

Berdasarkan pelayanan jaminan, mayoritas responden menilai tenaga kesehatan adalah tidak baik sebanyak 53 orang $(55,8 \%)$ dan minoritas responden menilai tenaga kesehatan adalah baik sebanyak 42 orang $(44,2 \%)$.

Berdasarkan pelayanan empati, mayoritas responden menilai tenaga kesehatan adalah baik sebanyak 63 orang $(66,3 \%)$ dan minoritas responden menilai tenaga kesehatan adalah tidak baik sebanyak 32 orang $(33,7 \%)$.

Berdasarkan pelayanan bukti fisik, mayoritas responden menilai tenaga kesehatan adalah tidak baik sebanyak 54 orang $(56,8 \%)$ dan minoritas responden menilai tenaga kesehatan sebanyak 41 orang $(43,2 \%)$.

Ditinjau dari kepuasan pasien, mayoritas responden menyatakan tidak puas sebanyak 49 orang $(51,6 \%)$ dan minoritas responden menyatakan puas sebanyak 46 orang $(48,4 \%)$.

\section{Analisis Bivariat}

Tabel 3. Hubungan Kehandalan Dengan Kepuasan Pasien Rawat Jalan di Puskesmas Sei Agul.

\begin{tabular}{|c|c|c|c|c|c|c|c|}
\hline \multirow{3}{*}{ Kehandalan } & \multicolumn{4}{|c|}{ Kepuasan pasien } & & & \multirow[b]{2}{*}{ p value } \\
\hline & \multicolumn{2}{|c|}{ Puas } & \multicolumn{2}{|c|}{ Tidak Puas } & \multicolumn{2}{|c|}{ Total } & \\
\hline & $\mathbf{n}$ & $\%$ & $\mathbf{n}$ & $\%$ & $\mathbf{N}$ & $\%$ & \\
\hline Baik & 30 & 63,8 & 17 & 36,2 & 47 & 100,0 & 0,006 \\
\hline Tidak Baik & 16 & 33,3 & 32 & 66,7 & 48 & 100,0 & \\
\hline
\end{tabular}

Sumber : Data Primer, 2019 
Berdasarkan tabel 3, diatas diketahui bahwa dari 47 responden yang menilai kehandalan baik, mayoritas responden menyatakan puas sebanyak 30 orang $(63,8 \%)$ dan minoritas responden menyatakan tidak puas sebanyak 17 orang $(36,2 \%)$. Dari 48 responden yang menilai kehandalan tidak baik, mayoritas responden menyatakan tidak puas sebanyak 32 orang $(66,7 \%)$ dan minoritas responden menyatakan puas sebanyak 16 orang $(33,3 \%)$.

Hasil analisis bivariat dengan menggunakan uji Chi Square diperoleh nilai $p$ value $=0,006(p$ value $<0,05$ ) artinya Ho ditolak, ini menunjukkan bahwa ada hubungan yang signifikan antara kehandalan dengan kepuasan pasien rawat jalan di Puskesmas Sei Agul.

Tabel 4. Hubungan Daya Tanggap Dengan Kepuasan Pasien Rawat Jalan di Puskesmas Sei Agul.

\begin{tabular}{|c|c|c|c|c|c|c|c|}
\hline \multirow{3}{*}{ Daya Tanggap } & \multicolumn{4}{|c|}{ Kepuasan pasien } & & & \multirow[b]{2}{*}{$p$ value } \\
\hline & \multicolumn{2}{|c|}{ Puas } & \multicolumn{2}{|c|}{ Tidak Puas } & \multicolumn{2}{|c|}{ Total } & \\
\hline & $\mathbf{n}$ & $\%$ & $\mathbf{n}$ & $\%$ & $\mathbf{N}$ & $\%$ & \\
\hline Baik & 29 & 67,4 & 14 & 32,6 & 43 & 100,0 & 0,002 \\
\hline Tidak Baik & 17 & 32,7 & 35 & 67,3 & 52 & 100,0 & \\
\hline
\end{tabular}

Sumber : Data Primer, 2019

Berdasarkan tabel 4, diatas diketahui bahwa dari 43 responden yang menilai daya tanggap baik, mayoritas responden menyatakan puas sebanyak 29 orang $(67,4 \%)$ dan minoritas responden menyatakan tidak puas sebanyak 14 orang $(32,6 \%)$. Dari 52 responden yang menilai daya tanggap tidak baik, mayoritas responden menyatakan tidak puas sebanyak 35 orang $(67,3 \%)$ dan minoritas responden menyatakan puas sebanyak 17 orang (32,7\%).

Hasil analisis bivariat dengan menggunakan uji Chi Square diperoleh nilai $p$ value $=0,002(p$ value $<0,05$ ) artinya Ho ditolak, ini menunjukkan bahwa ada hubungan yang signifikan antara daya tanggap dengan kepuasan pasien rawat jalan di Puskesmas Sei Agul.

Tabel .5. Hubungan Jaminan Dengan Kepuasan Pasien Rawat Jalan di Puskesmas Sei Agul.

\begin{tabular}{|c|c|c|c|c|c|c|c|}
\hline \multirow{3}{*}{ Jaminan } & \multicolumn{4}{|c|}{ Kepuasan pasien } & & & \multirow[b]{2}{*}{ p value } \\
\hline & \multicolumn{2}{|c|}{ Puas } & \multicolumn{2}{|c|}{ Tidak Puas } & \multicolumn{2}{|c|}{ Total } & \\
\hline & $\mathbf{n}$ & $\%$ & $\mathbf{N}$ & $\%$ & $\mathbf{N}$ & $\%$ & \\
\hline Baik & 28 & 66,7 & 14 & 33,3 & 42 & 100,0 & 0,003 \\
\hline Tidak Baik & 18 & 34,0 & 35 & 66,0 & 53 & 100,0 & \\
\hline
\end{tabular}

Sumber : Data Primer, 2019

Berdasarkan tabel 5, diatas diketahui bahwa dari 42 responden yang menilai jaminan baik, mayoritas responden menyatakan puas sebanyak 28 orang $(66,7 \%)$ dan minoritas responden menyatakan puas sebanyak 14 orang $(33,3 \%)$. Dari 53 responden yang menilai jaminan tidak baik, mayoritas responden menyatakan tidak puas sebanyak 35 orang $(66,0 \%)$ dan minoritas responden menyatakan puas sebanyak 18 orang $(34,0 \%)$.

Hasil analisis bivariat dengan menggunakan uji Chi Square diperoleh nilai $p$ value $=0,003(p$ value $<0,05$ ) artinya Ho ditolak, ini menunjukkan bahwa ada hubungan yang signifikan antara jaminan dengan kepuasan pasien rawat jalan di Puskesmas Sei Agul.

Tabel 6. Hubungan Empati Dengan Kepuasan Pasien Rawat Jalan di Puskesmas Sei Agul. 


\begin{tabular}{|c|c|c|c|c|c|c|c|}
\hline \multirow{3}{*}{ Empati } & \multicolumn{4}{|c|}{ Kepuasan pasien } & \multirow{2}{*}{\multicolumn{2}{|c|}{ Total }} & \multirow{2}{*}{ p value } \\
\hline & \multicolumn{2}{|c|}{ Puas } & \multicolumn{2}{|c|}{ Tidak Puas } & & & \\
\hline & $\mathbf{n}$ & $\%$ & $\mathbf{n}$ & $\%$ & $\mathbf{N}$ & $\%$ & \multirow{3}{*}{0,386} \\
\hline Baik & 33 & 52,4 & 30 & 47,6 & 63 & 100,0 & \\
\hline Tidak Baik & 13 & 40,6 & 19 & 59,4 & 32 & 100,0 & \\
\hline
\end{tabular}

Sumber : Data Primer, 2019

Berdasarkan tabel 6, diatas diketahui bahwa dari 63 responden yang menilai empati baik, mayoritas responden menyatakan puas sebanyak 33 orang $(52,4 \%)$ dan minoritas responden menyatakan tidak puas sebanyak 30 orang $(47,6)$. Dari 32 responden yang menilai empati tidak baik, mayoritas responden menyatakan tidak puas sebanyak 19 orang $(59,4 \%)$ dan minoritas responden menyatakan puas sebanyak 13 orang $(40,6 \%)$.

Hasil analisis bivariat dengan menggunakan uji Chi Square diperoleh nilai $p$ value $=0,386(p$ value $>0,05$ ) artinya Ho diterima, ini menunjukkan bahwa tidak ada hubungan yang signifikan antara empati dengan kepuasan pasien rawat jalan di Puskesmas Sei Agul.

Tabel 7. Hubungan Bukti Fisik Dengan Kepuasan Pasien Rawat Jalan di Puskesmas Sei Agul.

\begin{tabular}{|c|c|c|c|c|c|c|c|}
\hline \multirow{3}{*}{ Bukti Fisik } & \multicolumn{4}{|c|}{ Kepuasan pasien } & & & \multirow[b]{2}{*}{$p$ value } \\
\hline & \multicolumn{2}{|c|}{ Puas } & \multicolumn{2}{|c|}{ Tidak Puas } & \multicolumn{2}{|c|}{ Total } & \\
\hline & $\mathbf{n}$ & $\%$ & $\mathbf{n}$ & $\%$ & $\mathbf{N}$ & $\%$ & \\
\hline Baik & 26 & 63,4 & 15 & 36,6 & 41 & 100,0 & 0,019 \\
\hline Tidak Baik & 20 & 37,0 & 34 & 63,0 & 54 & 100,0 & \\
\hline
\end{tabular}

Berdasarkan tabel 7, diatas diketahui bahwa dari 41 responden yang menilai bukti fisik baik, mayoritas responden menyatakan puas sebanyak 26 orang $(63,4 \%)$ dan minoritas responden menyatakan tidak puas sebanyak 15 orang (36,6\%). Dari 54 responden yang menilai bukti fisik tidak baik, mayoritas responden menyatakan tidak puas sebanyak 34 orang $(63,0 \%)$ dan minoritas responden menyatakan puas sebanyak 20 orang $(37,0 \%)$.

Hasil analisis bivariat dengan menggunakan uji Chi Square diperoleh nilai $p$ value $=0,019$ ( $p$ value $<0,05$ ) artinya Ho ditolak, ini menunjukkan bahwa ada hubungan yang signifikan antara bukti fisik dengan kepuasan pasien rawat jalan di Puskesmas Sei Agul.

\section{PEMBAHASAN}

Hubungan Kehandalan dengan Kepuasan Pasien Rawat Jalan di Puskesmas Sei Agul.

Berdasarkan hasil analisis bivariat dengan menggunakan uji Chi Square diperoleh nilai $p$ value $=0,006(p$ value $<0,05)$ dan $\alpha=0,05$, maka Ho ditolak yang berarti ada hubungan kehandalan dengan kepuasan pasien rawat jalan di Puskesmas Sei Agul.

Menurut asumsi peneliti dari 48 responden yang menilai kehandalan tidak baik, mayoritas menyatakan tidak puas yaitu dikarenakan prosedur penerimaan pasien tidak dilayani secara cepat, sehingga pasien terlalu lama menunggu untuk mendapatkan pelayanan kesehatan. Lamanya pelayanan yang diberikan oleh tenaga kesehatan yang membutuhkan waktu proses pemeriksaan yang lama akan menyebabkan pasien merasa kurang puas terhadap pelayanan kehandalan tenaga kesehatan. Asumsi tersebut sesuai dengan teori Jusriani, dkk (2016) bahwa pelayanan yang berbelit-belit dan lamanya masa tunggu pasien dapat menentukan mutu pelayanan kesehatan karena membuat pasien merasa tidak dilayani dengan baik sehingga hal ini akan dapat menimbulkan ketidak puasan. ${ }^{4}$

Diketahui bahwa responden yang menilai kehandalan tidak baik namun menyatakan puas yaitu dikarenakan tenaga kesehatan selalu memberi obat pasien sesuai prosedur pemberian obat sehingga hal ini dapat menimbulkan rasa puas pada diri pasien. Hal ini sejalan dengan teori Andoko, dkk (2018) 
yang menyatakan bahwa petugas memberitahu dengan jelas tentang hal-hal yang harus dipatuhi dalam pengobatan serta petugas memberitahu dengan jelas tentang hal-hal yang dilarang dalam pengobatan sehingga persepsi kehandalan yang kurang baik dapat tertutupi oleh tindakan petugas yang lain sehingga responden merasa puas. ${ }^{5}$

Adanya 47 responden yang menilai kehandalan baik, mayoritas menyatakan puas. Hal ini dikarenakan tenaga kesehatan terlihat terampil dan handal dalam memberikan pelayanan kesehatan sehingga banyak pasien merasa puas. Hal ini sejalan dengan teori Pangerapan, dkk (2018) yang menyatakan bahwa semakin baik kehandalan maka pasien juga akan merasa puas terhadap pelayanan kesehatan yang diberikan. $^{6}$

Diketahui bahwa responden yang menilai kehandalan baik namun menyatakan tidak puas yaitu dikarenakan tenaga kesehatan tidak memberitahu pasien secara jelas terhadap penyakit atau keluhan yang dihadapi pasien. Hal ini sejalan dengan teori Andoko, dkk (2018) yang menyatakan bahwa tidak semua responden merasa bahwa petugas memberikan informasi dengan jelas sehingga beberapa responden mengungkapkan walaupun kehandalan baik namun karena informasi yang disampaikan kurang jelas membuat persepsi yang baik menjadi kurang puas. ${ }^{5}$

\section{Hubungan Daya Tanggap dengan Kepuasan Pasien Rawat Jalan di Puskesmas Sei Agul}

Berdasarkan hasil analisis bivariat dengan menggunakan uji Chi Square diperoleh nilai $p$ value $=0,002(p$ value $<0,05)$ dan $\alpha=0,05$, maka Ho ditolak yang berarti ada hubungan daya tanggap dengan kepuasan pasien rawat jalan di Puskesmas Sei Agul.

Menurut asumsi peneliti dari 52 responden yang menilai daya tanggap tidak baik mayoritas menyatakan tidak puas karena tenaga kesehatan kurang cepat dan tanggap dalam memberikan pelayanan kesehatan kepada pasien. Tenaga kesehatan kurang memahami apa yang dibutuhkan pasien dan tenaga kesehatan jarang memberikan kesempatan bertanya kepada pasien sehingga pasien tidak dapat berkonsultasi tentang penyakitnya. Asumsi tersebut sesuai dengan teori Pangerapan, dkk (2018) yang menyatakan bahwa sangat penting akan adanya petugas kesehatan yang cepat tanggap dalam melayani pelanggan/pasien. Daya tanggap petugas dalam melayani pasien/klien berhubungan erat dengan kepuasan pasien. $^{6}$

Diketahui bahwa responden yang menilai daya tanggap tidak baik namun menyatakan puas dikarenakan tenaga kesehatan selalu mendahulukan pasien yang mengantri untuk mendapatkan pelayanan kesehatan dan tenaga kesehatan selalu memberikan alternatif pemecahan masalah jika terjadi hambatan dalam pelayanan kesehatan yang diterima oleh pasien. Responden menilai daya tanggap pelayanan tenaga kesehatan kurang maksimal namun merasa puas terhadap tindakan tenaga kesehatan terhadap kebutuhan pasien. Hal ini sejalan dengan teori Pangerapan, dkk (2018) bahwa daya tanggap sebagai suatu sikap tanggap tenaga kesehatan melayani saat dibutuhkan pasien berkaitan erat dengan kepuasan pasien. ${ }^{6}$

Menurut asumsi peneliti dari 43 responden yang menilai daya tanggap baik, mayoritas menyatakan puas. Hal ini dikarenakan tenaga kesehatan sudah melakukan tindakan pelayanan kesehatan sesuai dengan prosedur dan tenaga kesehatan juga memberikan informasi sebelum tindakan pelayanan dilakukan kepada pasien. Responden yang menilai pelayanan daya tanggap baik namun menyatakan tidak puas yaitu dikarenakan kurangnya kesediaan tenaga kesehatan dalam membantu pasien untuk mendapatkan pelayanan kesehatan dan tenaga kesehatan tidak memberikan kesempatan kepada pasien untuk bertanya sehingga pasien merasa tidak puas.

Sesuai dengan teori Jusriani, dkk (2016) kesediaan petugas untuk membantu pasien, merespon dan memberikan pelayanan yang cepat yang meliputi kecepatan petugas dalam menangani keluhan pasien serta kesigapan petugas dalam melayani pasien dapat meningkatkan kepuasan pasien. ${ }^{4}$

\section{Hubungan Jaminan Dengan Kepuasan Pasien Rawat Jalan di Puskesmas Sei Agul}

Berdasarkan hasil analisis bivariat dengan menggunakan uji Chi Square diperoleh nilai $p$ value $=0,003(p$ value $<0,05)$ dan $\alpha=0,05$, maka Ho ditolak, yang berarti ada hubungan antara jaminan dengan kepuasan 
pasien rawat jalan di Puskesmas Sei Agul.

Menurut asumsi peneliti dari 53 responden yang menilai jaminan tidak baik mayoritas menyatakan tidak puas dikarenakan tenaga kesehatan tidak memberikan informasi yang jelas tentang keluhan yang diderita pasien dan tenaga kesehatan juga kurang bersikap ramah dalam memberikan pelayanan kepada pasien sehingga banyak pasien yang merasa tidak puas. Asumsi tersebut sesuai dengan teori Jusriani, dkk (2016) yang menyatakan bahwa adanya hubungan yang erat antara keramahan petugas, kemudahan pasien mendapatkan pelayanan dan informasi dapat terpenuhi dengan penamfaatan ulang pelayanan sehingga dapat meningkatkan kepuasan pada pasien. ${ }^{4}$

Diketahui bahwa responden yang menilai jaminan pelayanan tidak baik namun menyatakan puas. Hal ini dikarenakan tenaga kesehatan selalu sabar mendengarkan keluhan pasien serta memberikan solusi untuk mengatasi masalah pasien sehingga pasien merasa nyaman dan menimbulkan rasa puas. Hal ini sesuai dengan teori Pangerapan, dkk (2018) bahwa Setiap pasien pada dasarnya ingin diperlakukan secara baik oleh tenaga kesehatan akan memberi rasa aman kepada pasien. Jika persepsi pasien terhadap jaminan baik maka kepuasan pasien akan semakin tinggi. $^{6}$

Menurut asumsi peneliti dari 42 responden yang menilai jaminan pelayanan baik, mayoritas menyatakan puas yaitu dikarenakan perilaku tenaga kesehatan terhadap pasien menimbulkan rasa kepercayaan dan keyakinan untuk sembuh sehingga pengobatan yang diberikan oleh tenaga kesehatan mampu mengatasi penyakit pasien. Tenaga kesehatan juga selalu menjaga kerahasiaan tentang penyakit pasien selama pengobatan. Dari perlakuan tenaga kesehatan terhadap pasien yang diterima oleh responden sehingga didapatkan kepuasan kepada pasien.

Diketahui bahwa responden yang menilai jaminan pelayanan baik namun menyatakan tidak puas. Hal ini dikarenakan kurangnya kelancaran komunikasi tenaga kesehatan kepada pasien dan saat berkomunikasi tenaga kesehatan tidak menggunakan bahasa yang mudah dimengerti oleh pasien tentang masalah penyakit yang dideritanya sehingga pasien merasa kurang puas.
Asumsi ini sesuai dengan teori Pangerapan, dkk (2018) bahwa Jaminan meliputi kemampuan atas keterampilan petugas dalam memberikan informasi, kemampuan dalam memberikan keamanan dan kemampuan di dalam menanamkan kepercayaan pasien terhadap petugas kesehatan. ${ }^{6}$

\section{Hubungan Empati Dengan Kepuasan Pasien Rawat Jalan di Puskesmas Sei Agul}

Berdasarkan hasil analisis bivariat dengan menggunakan uji Chi Square diperoleh nilai $p$ value $=0,386(p$ value $>0,05)$ dan $\alpha=0,05$, maka Ho diterima, yang berarti tidak ada hubungan empati dengan kepuasan pasien rawat jalan di Puskesmas Sei Agul.

Menurut asumsi peneliti dari 63 responden yang menilai pelayanan empati baik, mayoritas menyatakan puas. Hal ini menunjukkan bahwa tenaga kesehatan selalu memberikan salam atau sapaan kepada pasien sebelum diperiksa karena pasien sangat membutuhkan dukungan dan pelayanan yang ramah dengan senyum, sapa dan salam itu akan dapat membuat pasien merasa dilayani dengan baik dan penuh rasa sabar sehingga akan membantu dalam proses penyembuhan pada diri pasien.

Responden yang menilai pelayanan empati baik namun menyatakan tidak puas. Hal ini dikarenakan tenaga kesehatan kurang memperhatikan kebutuhan pasien. Tenaga kesehatan tidak meluangkan waktu khusus untuk berkomunikasi dengan pasien dan keluarga sehingga tidak terpenuhinya berkonsultasi antara keluarga pasien dengan dokter. Tenaga kesehatan juga kurang memberi perhatian terhadap keluhan pasien sehingga pasien merasa tidak puas .

Asumsi tersebut sesuai dengan teori Suparta, dkk (2018) menyatakan bahwa Kemampuan petugas kesehatan untuk memberikan perhatian yang tulus terhadap semua pasien. Perhatian diukur dengan indikator pelayanan, keramahan yang sama tanpa memandang status pasien, dapat memberikan perhatian kepada setiap pasiennya,

Menurut asumsi peneliti dari 32 responden yang menilai pelayanan empati tidak baik, mayoritas tidak puas yaitu dikarenakan tenaga kesehatan tidak meluangkan waktu 
untuk melayani setiap keluhan yang diderita pasien dan tenaga kesehatan juga kurang memberikan dukungan kepada pasien untuk sembuh serta kurangnya perhatian dokter terhadap keluhan pasien.

Responden yang menilai pelayanan empati tidak baik namun menyatakan puas yaitu dikarenakan tenaga kesehatan selalu menjelaskan jadwal minum obat kepada pasien sehingga pasien mengetahuinya dengan jelas. Walaupun tenaga kesehatan tidak meluangkan waktunya untuk berkonsultasi kepada pasien, akan tetapi tenaga kesehatan selalu memberikan penyuluhan tentang penyakit yang diderita pasien. Sehingga pasien mendapatkan informasi tentang penyembuhan dan penanggulangan terhadap penyakit pasien.

Asumsi tersebut sesuai dengan teori Jusriani, dkk (2018) yang menyatakan bahwa Penilaian persepsi empati pada penelitian ini meliputi petugas kesehatan meluangkan waktu khusus untuk berkomunikasi dengan pasien, petugas selalu mengingatkan keamanan akan menyimpan barang berharga pasien dan keluarganya, waktu untuk berkonsultasi keluarga pasien terpenuhi, dan menghibur dan memberikan dorongan kepada pasien supaya cepat sembuh dan mendoakan mereka. ${ }^{4}$

\section{Hubungan Bukti Fisik Dengan Kepuasan Pasien Rawat Jalan di Puskesmas Sei Agul}

Berdasarkan hasil analisis bivariat dengan menggunakan uji Chi Square diperoleh nilai $p$ value $=0,019(p$ value $<0,05)$ dan $\alpha=0,05$, maka Ho ditolak, yang berarti ada hubungan bukti fisik dengan kepuasan pasien rawat jalan di Puskesmas Sei Agul.

Menurut asumsi peneliti dari 54 responden yang menilai pelayanan bukti fisik tidak baik, mayoritas menyatakan tidak puas yaitu dikarenakan fasilitas ruang tunggu yang belum memadai seperti fasilitas tempat duduk yang belum memadai sehingga menyebabkan ketidaknyamanan pada pasien sehingga banyak pasien yang merasa tidak puas. Asumsi tersebut sesuai dengan teori Jusriani, dkk (2016) menyatakan bahwa ruang tunggu pasien yang terbatas membuat kondisi ruang tunggu sangat sesak dan padat. Hal ini membuat beberapa pasien harus menunggu dengan berdiri. ${ }^{4}$

Responden yang menilai pelayanan bukti fisik tidak baik namun menyatakan puas yaitu dikarenakan pelayanan bukti fisik dipengaruhi oleh tidak maksimalnya kebersihan pada alat- alat pemeriksaan. Bangunan unit puskesmas tertata dengan rapi, puskesmas memiliki papan petunjuk yang jelas sehingga pasien mudah untuk mendapatkan pelayanan kesehatan.

Penelitian ini didukung oleh teori Muninjaya (2018) bahwa bukti fisik (tangibles) dapat dirasakan secara langsung oleh para penggunanya dengan menyediakan fasilitas fisik dan perlengkapan yang memadai. Para penyedia layanan akan mampu bekerja secara optimal sesuai dengan keterampilan masingmasing. ${ }^{8}$

Diketahui bahwa 41 responden yang menilai pelayanan bukti fisik baik, mayoritas menyatakan puas yaitu dikarenakan obat di Puskesmas Sei Agul selalu tersedia dan penampilan tenaga kesehatan selalu bersih dan rapi sehingga membuat pasien merasa nyaman untuk mendapatkan pelayanan kesehatan. Sedangkan responden yang menilai pelayanan baik namun menyatakan tidak puas yaitu dikarenakan kurangnya kebersihan diruang tunggu pemeriksaan dan di lingkungan Puskesmas Sei Agul serta area parkiran yang kurang luas bagi pasien.

\section{KESIMPULAN DAN SARAN}

Berdasarkan penelitian yang telah dilakukan dapat disimpulkan sebagai berikut: Ada hubungan kehandalan dengan kepuasan pasien rawat jalan ruang poli umum di Puskesmas Sei Agul dengan nilai $p$ value $=$ 0,006 . Ada hubungan daya tanggap dengan kepuasan pasien rawat jalan ruang poli umum di Puskesmas Sei Agul dengan nilai $p$ value $=$ 0,002 . Ada hubungan jaminan dengan kepuasan pasien rawat jalan ruang poli umum di Puskesmas Sei Agul dengan nilai $p$ value $=$ 0,003 . Tidak ada hubungan empati dengan kepuasan pasien rawat jalan ruang poli umum di Puskesmas Sei Agul dengan nilai $p$ value $=$ 0,386 . Ada hubungan bukti fisik dengan kepuasan pasien rawat jalan ruang poli umum di Puskesmas Sei Agul dengan nilai $p$ value $=$ 0,019 . Saran yang dapat penulis simpulkan dari hasil penelitian ini yaitu Diharapkan kepada pihak Puskesmas Sei Agul untuk melengkapi fasilitas kesehatan yang masih kurang dan diharapkan dapat meningkatkan mutu pelayanan kesehatan . 


\section{REFERENSI}

1. Kemenkes, RI. (2015). Laporan

Akuntabilitas Kinerja Kementerian Kesehatan Tahun 2014.

2. Kementerian Kesehatan. Profil Kesehatan Kota Medan Tahun2016.

3. Munsil, dkk. (2017). AnalisisKepuasan Pasien Terhadap Mutu Pelayanan Kesehatan Pada Poli Jantung Dengan Metode Ipa (Importance Performance Analysis) Di Rsud Bahteramas Provinsi Sulawesi Tenggara Tahun 2017 [Halu Oleo].

4. Jusriani, Junaid, \& Lisnawaty. (2016). Hubungan Mutu Pelayanan Kesehatan Dengan Kepuasan Pasien Rawat Jalan Puskesmas Puriala Kecamatan Puriala Kabupaten Konawe Tahun 2016. Jurnal Kesehatan Masyarakat.

5. Andoko, Norman, H., \& Novalina, D.(2018). Hubungan mutu pelayanan terhadap tingkat kepuasan pasien rawat jalan di Puskesmas Way Halim Kota Bandar Lampung Tahun 2018. Holistik Jurnal Kesehatan, 12(2), 92102.

6. Pangarepan, dkk. 2018. Hubungan Antara Mutu Pelayanan Dengan Kepuasan Pasien Di Poliklinik Penyakit Dalam Rumah Sakit Umum GMIM Pancaran Kasih Manado. Jurnal Kedokteran. Vol 2 No 1.

7. Suparta, Haryono, \& Kamsir, A. (2018). Hubungan Mutu Pelayanan Terhadap Kepuasan Pasien Di Poli Umum Puskesmas Lompoe Kota Pare-Pare. Jurnal IImiah Kesehatan Pencerah, 7, 54-63.

8. Muninjaya, A. A. Gde. (2018). Manajemen Mutu Pelayanan Kesehatan. Buku Kedokteran EGC. 